\title{
The response of Culex quinquefasciatus (Diptera: Culicidae) to traps baited with carbon dioxide, 1-octen-3-ol, acetone, butyric acid and human foot odour in Tanzania
}

\author{
L.E.G. Mboera ${ }^{1}$, W. Takken ${ }^{2 *}$ and E.Z. Sambu ${ }^{1}$ \\ ${ }^{1}$ National Institute for Medical Research, Ubwari Field Station, PO Box 81, \\ Muheza, Tanzania: ${ }^{2}$ Laboratory of Entomology, Wageningen Agricultural \\ University, PO Box 8031, $6700 \mathrm{EH}$, Wageningen, The Netherlands
}

\begin{abstract}
The responses of Culex quinquefasciatus Say to traps baited with carbon dioxide, 1-octen-3-ol, acetone, butyric acid and human foot odour were studied in the field in Muheza, north-east Tanzania using Counterflow Geometry (CFG) and Centers for Disease Control (CDC) traps. It was found that significantly more C. quinquefasciatus responded to foot odour collected on nylon stockings than to clean nylon stockings $(P<0.05)$. Significantly more mosquitoes were caught in a CFG trap baited with carbon dioxide than in traps with either human foot odour, acetone or butyric acid. It was also found that in an outdoor situation a carbon dioxide baited CDC unlit trap collected over 12 times more C. quinquefasciatus than an unbaited CDC unlit trap and nine times more mosquitoes than CDC traps baited with 1-octen-3-ol alone $(P<0.05)$. The number of mosquitoes caught in a CDC trap baited with 1-octen-3-ol did not differ significantly from that of the unbaited CDC trap $(P>0.05)$. These results indicate that the Afrotropical $C$. quinquefasciatus respond significantly better to traps baited with carbon dioxide than to either octenol, acetone or butyric acid, and that human foot odour contains stimuli to which C. quinquefasciatus is attracted under field conditions.
\end{abstract}

\section{Introduction}

Blood-seeking mosquitoes (Diptera: Culicidae) use airborne olfactory cues produced by their hosts to orientate towards them. Human body odour is probably the most important cue in the host-seeking behaviour of nocturnal anthropophilic mosquitoes (Takken \& Knols, 1999). Odours are considered long distance cues employed by mosquitoes, while in the vicinity of the host, the insects may respond to other signals such as temperature, moist air and movement (Gillies, 1988). In recent years, several workers have

*Address for correspondence: Laboratory of Entomology, Wageningen Agricultural University, PO Box 8031, 6700 EH, Wageningen, The Netherlands

Fax +31 317484821

E-mail: willem.takken@users.ento.wau.nl demonstrated the behavioural significance of chemical compounds as a source of attractants for anthropophilic mosquitoes (Cork, 1996; Cork \& Park, 1996; Geier et al., 1996; Knols et al., 1997; Takken et al., 1997). The olfactory stimuli implicated in host location by haematophagous insects to date include carbon dioxide, lactic acid, acetone, butanone, 1-octen-3-ol (henceforth referred to as octenol), phenolic components of urine (Hassanali et al., 1986; Bursell et al., 1988) and short-chain carboxylic acids (Knols et al., 1997).

Many mosquitoes respond to carbon dioxide, a universal compound produced by all vertebrates, and its role in host finding by mosquitoes has been recently reviewed comprehensively by Mboera \& Takken (1997). However, for host-seeking anthropophilic mosquitoes such as Anopheles gambiae Giles sensu stricto and Culex quinquefasciatus Say, the role of carbon dioxide may not be as important as in many other mosquito species although in the field this compound does contribute to the process of host location in both 
species (Costantini et al., 1996; Mboera et al., 1997; Dekker \& Takken, 1998). Next to carbon dioxide, other emanations of human and/or animal origin are assumed to play a role in host location of mosquitoes, although few compounds have been identified to-date (Takken \& Knols, 1999).

Octenol and acetone, which were first identified as host attractants for tsetse flies (Hall et al., 1984; Hassanali et al., 1986), have been shown to attract certain mosquito species in the field. The established role of octenol as a kairomone for many mosquito species has been well documented (Kline, 1994). Most of these studies have demonstrated that octenol, in combination with carbon dioxide, significantly increased collections of Aedes mosquitoes. However, the response of many mosquito species to octenol is poor in the absence of carbon dioxide. Recently, it was shown that the anthropophilic C. quinquefasciatus is attracted to human foot odour in the laboratory (Mboera et al., 1998), while Kline (1998) showed that several other culicine mosquitoes were attracted to this odour source in the field in the United States. These odour sources, and others, have not been previously tested as mosquito attractants under field conditions in East Africa. Such attractants are needed as odour baits in surveillance studies of malaria and filariasis vectors, as odour-baited traps are expected to replace the ethically unacceptable human biting catch technique (Gibson, 1996). The studies reported here were, therefore, conducted to evaluate, in the field, carbon dioxide, octenol, acetone, butyric acid and foot odour as attractants for $C$. quinquefasciatus, a serious nuisance mosquito and vector of urban bancroftian filariasis, under field conditions of northeastern Tanzania. Carbon dioxide was chosen to serve as a reference compound to compare with the effect of other odours and to investigate whether it caused synergism with octenol.

\section{Materials and methods}

\section{Study area}

Field studies were conducted in Muheza $\left(5^{\circ} 10^{\prime} \mathrm{S}\right.$, $38^{\circ} 46^{\prime} \mathrm{E}$ ) in north-east Tanzania, about $40 \mathrm{~km}$ west of the coastal town of Tanga. The area lies in the foothills of the East Usambara mountains at an altitude of $200 \mathrm{~m}$ above sea level. Mean temperatures vary from $22.5^{\circ} \mathrm{C}$ in July to $27^{\circ} \mathrm{C}$ in February. There are two rainy seasons: the long rains from March to May and the short rains from November to December. The annual rainfall amounts to an average of $1000 \mathrm{~mm}$ per annum. Most of the inhabitants in the study area live in houses made of mud walls and iron roofing and many of the houses have pit latrines. Culex quinquefasciatus breeds mainly in pit latrines and soakage pits and is the dominant mosquito species in the study area.

\section{Traps}

In this study, two different traps for the sampling of adult mosquitoes were used: the Counterflow Geometry (CFG) trap and the miniature Centers for Disease Control (CDC) trap. The CFG trap (American Biophysics Corporation, East Greenwich, Rhode Island, USA), which utilizes a novel counterflow concept, has been described recently by Kline (1999). The CDC traps (Model 512, John W. Hock Company, Gainesville, Florida, USA) were as described by Sudia \& Chamberlain (1962).) The CFG trap was found to be superior to the CDC trap as an odour-baited sampling device for mosquitoes, including C. quinquefasciatus (Kline, 1999; Mboera et al., 2000).

\section{Experimental protocol}

The response of $\mathrm{C}$. quinquefasciatus to a Counterflow Geometry trap baited with foot odour versus an unbaited trap

Two CFG traps were used in this experiment. One of the traps was baited with a nylon stocking, worn for four to seven days on a male volunteer (40 years old, $70 \mathrm{~kg}$ body weight) while the other trap was baited with a clean nylon stocking of the same brand as the worn stocking. The stockings were put into a polythene bag, fixed to the trap at its carbon dioxide supply point, through a $20 \mathrm{~cm}$ long $(5 \mathrm{~mm}$ inside diameter) silicon tubing. The traps were hung from a wooden pole $25 \mathrm{~m}$ apart and $30 \mathrm{~m}$ from the nearest house with the lowest part $20 \mathrm{~cm}$ from the ground. The treatments were alternated between the two sites every trapping day and the traps were operated between 19.00 and $06.00 \mathrm{~h}$ for four days.

The response of $\mathrm{C}$. quinquefasciatus to a CFG trap baited with carbon dioxide versus a trap baited with foot odour, acetone or butyric acid

Into one trap, carbon dioxide released at $300 \mathrm{ml} \mathrm{min}^{-1}$ was pumped from a pressurized cylinder, through a $5 \mathrm{~mm}$ silicon tubing. The second trap was baited with a nylon stocking worn for four to seven days. The stocking was put in a polythene bag fixed to the trap through a similar tubing, $20 \mathrm{~cm}$ long. The traps were hung from a wooden pole with the lowest part $20 \mathrm{~cm}$ from the ground. In another experiment, the response of $C$. quinquefasciatus to a CFG trap baited with carbon dioxide versus a CFG trap baited with acetone was assessed. In one trap, carbon dioxide was pumped from a pressurized cylinder at a rate of $300 \mathrm{ml}$ $\min ^{-1}$. In another trap, a glass bottle containing $4 \mathrm{ml}$ of acetone was fixed to a silicon tube connected to the trap at its carbon dioxide supply point. The acetone was topped up daily to the $4 \mathrm{ml}$ mark before the start of the daily experiment. In another series of experiments, the response of C. quinquefasciatus to a carbon dioxide baited CFG trap versus a trap baited with butyric acid was assessed. Butyric acid was supplied from a 4-ml glass vial fitted to a silicon tubing fixed to the trap at its carbon dioxide supply point. In another trap, carbon dioxide released at $300 \mathrm{ml} \mathrm{min}^{-1}$ was pumped. During these experiments the treatments, $25 \mathrm{~m}$ apart and $30 \mathrm{~m}$ from the nearest house, were alternated between the two sites and the traps were operated between 19.00 and $06.00 \mathrm{~h}$ for four days.

The response of $\mathrm{C}$. quinquefasciatus to a CFG trap baited with carbon dioxide or foot odour versus a trap baited with carbon dioxide + foot odour

In this experiment, carbon dioxide released at $300 \mathrm{ml}$ $\mathrm{min}^{-1}$ was pumped into one CFG trap while in the other trap carbon dioxide at the same release rate was pumped through a polythene bag containing a nylon stocking worn for four to seven days. Carbon dioxide was released into the polythene bag through a $5 \mathrm{~mm}$ silicon tubing. In the third treatment, a polythene bag containing a nylon stocking worn for four to seven days was fixed to a CFG trap through its carbon dioxide supply point. The traps were $25 \mathrm{~m}$ apart in a straight line. At each site, the trap was hung from a wooden 
pole so that the bottom tube, through which the odour was released, was $20 \mathrm{~cm}$ above the ground level. In this experiment, traps were assigned to the respective treatments and rotated daily between sites for three days between 18.00 and $06.00 \mathrm{~h}$.

The response of $\mathrm{C}$. quinquefasciatus to carbon dioxide, octenol and carbon dioxide + octenol combination

Because of an insufficient number of CFG traps, CDC traps from which the light had been removed (CDC unlit) were used in this experiment. Miniature CDC unlit traps were baited with the following odours: (i) carbon dioxide alone; (ii) octenol alone; (iii) carbon dioxide + octenol; and (iv) an unbaited CDC trap as a control. Three hundred millilitres $\mathrm{min}^{-1}$ of carbon dioxide was dispensed from a pressurized gas cylinder as described in experiment 2 . The outlet of the tubing was fixed at the entrance of a CDC trap. Four millilitres of octenol was dispensed from glass vials with a pipe-cleaner extending $2 \mathrm{~cm}$ above the septum (see Kline et al., 1990). Each trap day the octenol level was adjusted to $4 \mathrm{ml}$ and the vial inverted for several seconds to ensure complete wick saturation. Vials were affixed near the trap entrance and when used in combination with carbon dioxide, they were affixed adjacent to the carbon dioxide release point. The traps were hung outdoors from wooden poles, with the trap shield at $1 \mathrm{~m}$ from the ground. The treatments were $25 \mathrm{~m}$ apart in a straight line and $30 \mathrm{~m}$ from the nearest house. Each trap position was provided with a different bait in a randomized design from 19.00 to $06.00 \mathrm{~h}$ for four days.

\section{Data analysis}

All mosquito catches were transformed to $\log (n+1)$ and were subjected to a Latin square analysis of variance (Snedecor \& Cochran, 1989). An F-test significant at $P<0.05$ was followed by a Least Significant Difference test to identify differences between treatment means.

\section{Results}

A total of 1508 mosquitoes were collected during the study period. The collections consisted of six species of

Table 1. Total (n) and geometric mean catches of Culex quinquefasciatus per day for a CFG trap baited with foot odour versus an unbaited trap (control) A; carbon dioxide versus a trap baited with: B, foot odour: C, acetone; and D, butyric acid. All experiments were conducted outdoors.

\begin{tabular}{|c|c|c|c|}
\hline & Bait & $\mathrm{n}$ & Mean \pm SE \\
\hline \multirow[t]{2}{*}{ A } & Control & 10 & $2.3 \pm 0.2 \mathrm{a}$ \\
\hline & Foot odour & 85 & $21.1 \pm 0.8 b$ \\
\hline \multirow[t]{2}{*}{ B } & Carbon dioxide & 143 & $35.3 \pm 0.1 \mathrm{a}$ \\
\hline & Foot odour & 49 & $11.9 \pm 0.2 b$ \\
\hline \multirow[t]{2}{*}{$\mathrm{C}$} & Carbon dioxide & 176 & $43.4 \pm 0.1 \mathrm{a}$ \\
\hline & Acetone & 22 & $3.4 \pm 0.7 \mathrm{~b}$ \\
\hline \multirow[t]{2}{*}{$\mathrm{D}$} & Carbon dioxide & 118 & $29.4 \pm 0.1 \mathrm{a}$ \\
\hline & Butyric acid & 16 & $3.5 \pm 0.3 b$ \\
\hline
\end{tabular}

$\mathrm{SE}=$ standard error. Means in the same column, within a subtable, followed by a different letter are significantly different at $P$ $<0.05$.
Table 2. Total (n) and geometric mean catches of Culex quinquefasciatus per day for a CFG trap baited with carbon dioxide versus a trap baited with foot odour or carbon dioxide + foot odour combination outdoors.

\begin{tabular}{llr}
\hline Bait & $\mathrm{n}$ & Mean \pm SE \\
\hline Carbon dioxide & 50 & $13.0 \pm 0.1 \mathrm{a}$ \\
Foot odour & 25 & $8.3 \pm 0.1 \mathrm{a}$ \\
Carbon dioxide + Foot odour & 86 & $27.6 \pm 0.2 \mathrm{a}$ \\
\hline
\end{tabular}

$\overline{\mathrm{SE}}=$ standard error. Means are followed by the same letter indicating that they are not significantly different.

mosquitoes, which in descending order of abundance were: C. quinquefasciatus (87.7\%), Anopheles gambiae Giles (2.9\%), Culex cinereus Theobald (2.1\%), Anopheles coustani Laveran $(1.8 \%)$, Anopheles funestus Giles (1.0\%) and Mansonia africana (Theobald) (0.9\%). Only C. quinquefasciatus numbers were considered adequate to include in the statistical analyses.

In all experiments there was no significant difference in catches between days or sites. Table 1A shows that significantly more mosquitoes responded to a CFG trap baited with foot odour than to an unbaited trap under field conditions. However, significantly more mosquitoes were caught in a trap baited with carbon dioxide than in a trap baited with foot odour $(P<0.05)$ (table 1B). Also significantly more mosquitoes responded to traps baited with carbon dioxide than with acetone. Similarly, a significantly larger number of mosquitoes was caught in traps baited with carbon dioxide than in traps baited with butyric acid $(P<0.05)$ (table $1 \mathrm{D})$. More mosquitoes were caught in a CFG trap baited with a combination of carbon dioxide and foot odour than to a trap baited with each stimulus separately, but the difference was not statistically significant (table 2). In this experiment, there was also no significant difference between a trap baited with carbon dioxide and one baited with foot odour.

Unlike in the previous experiments, studies with carbon dioxide and octenol were conducted with CDC traps. A carbon dioxide-baited CDC trap collected over 12 times more $C$. quinquefasciatus than an unbaited trap and nine times more mosquitoes than a trap baited with octenol alone $(P<0.05)$. Although fewer mosquitoes were caught in a trap baited with a combination of carbon dioxide + octenol than to carbon dioxide alone, the difference was not significant. It was further observed that the number of mosquitoes caught in the octenol-baited trap did not differ significantly from that caught in the unbaited trap $(P>0.05)$.

Table 3. Total (n) and geometric mean catches of Culex quinquefasciatus per day for CDC unlit trap baited with carbon dioxide $\left(\mathrm{CO}_{2}\right)$, octenol or their combination and an unbaited CDC unlit trap (control) outdoors.

\begin{tabular}{lrr}
\hline Bait & $\mathrm{n}$ & Mean \pm SE \\
\hline Control & 29 & $5.4 \pm 0.6 \mathrm{a}$ \\
Carbon dioxide & 297 & $65.3 \pm 0.3 \mathrm{~b}$ \\
Octenol & 33 & $7.0 \pm 0.4 \mathrm{a}$ \\
Carbon dioxide + Octenol & 184 & $40.5 \pm 0.4 \mathrm{~b}$ \\
\hline
\end{tabular}

$\mathrm{SE}=$ standard error. Mean not followed by the same letter are significantly different at $P<0.05$. 


\section{Discussion}

These experiments have shown that in the field, a trap baited with worn stockings caught a significantly larger number of $C$. quinquefasciatus than a trap baited with clean stockings. Kline (1998) also found in his field studies that a CFG trap baited with a worn sock collected significantly more mosquitoes of various species than an unbaited trap. Human foot odour, therefore, must be considered as a source of kairomones for C. quinquefasciatus even in the absence of other stimuli like moisture or body temperature (Mboera et al., 1998)

Although an earlier laboratory study showed no effect of carbon dioxide on $C$. quinquefasciatus whereas there was a strong response to foot odour (Mboera et al., 1998), the present study suggests that this mosquito is attracted to carbon dioxide. Indeed, one trial suggested that carbon dioxide is more attractive to $C$. quinquefasciatus than the emanations present on worn stockings, while another trial did not find a significant difference between either of these stimuli and their combination. Recently, Kline (1998) found a synergistic interaction between worn socks and carbon dioxide in attracting most species of mosquitoes in six genera (Aedes, Anopheles, Coquillettidia, Culex, Culiseta, and Psorophora) during his field studies in the United States. In the present study, however, there was no synergistic effect of carbon dioxide and foot odour, although the combination of foot odour and carbon dioxide collected more mosquitoes than the sum of each stimulus alone. Previous field studies in Kenya (Haddow, 1942) showed that other anthropophilic mosquitoes, A. gambiae and A. funestus females, preferred a hut containing worn clothing to a completely empty hut. Further studies by Carlson et al. (1973) and Knols et al. (1997) have shown that the anthropophilic Aedes aegypti (Linnaeus) and Anopheles gambiae s.s. are attracted to carboxylic acids (fatty acids) in the laboratory. Free fatty acids constitute a quarter of the skin surface lipid of humans and are breakdown products of triglycerides to free glycerol by the action of Corynebacterium and Pityrosporum, microorganisms residing in the sebaceous glands (Nicolaides, 1974). Therefore, carboxylic acids are likely to constitute one of the attractive stimuli present on a previously worn stocking. As there was evidence from one of the present trials that $C$. quinquefasciatus is relatively poorly attracted to human foot odour when compared with carbon dioxide, we have no explanation for the difference observed, other than the possibility that under the experimental field conditions other competitive odours may have been present or the foot odour may have lost essential components while being exposed to the ambient air. Also, no attempts were made to quantify the amount of human foot odour, whereas the concentration and dose of these stimuli may be very important in affecting host-seeking C. quinquefasciatus.

The results of this study are different from what has been observed when using live human baits in both indoor and outdoor situations in the field. Culex quinquefasciatus was observed to be significantly more attracted to human odourbaited tents than to carbon dioxide-baited tents in the same location in Tanzania (Mboera \& Takken, 1999). This has also been observed for the other Afrotropical anthropophilic mosquitoes, A. gambiae and A. funestus (Costantini et al., 1996; Mboera et al., 1997). The difference may be caused by the fact that live humans emit a wider range of cues than the foot odour collected on stockings.
In this study octenol was a poor mosquito attractant. Although Ritchie \& Kline (1995) showed that octenol supplemented with carbon dioxide significantly increased collections of Culex annulirostris Skuse in Australia, other Culex species have shown a weak response to octenol in similar studies elsewhere. For instance, in Germany, Culex pipiens Linnaeus did not respond to octenol (Becker et al., 1995), while from studies in the United States and Australia it is clear that few mosquito species respond to octenol alone, and many species, including several anophelines, responded only to a combination of octenol and carbon dioxide (Kline, 1994; Kline \& Lemire, 1995). Interestingly, Kline \& Lemire (1995) found a significant increase in trap collections when CDC traps were baited with carbon dioxide and octenol and heat was added as an additional stimulus. This suggests an interaction between heat and olfactory stimuli as had been proposed by Laarman (1958). Octenol is a common volatile in the emanations of herbivorous mammals (Hall et al., 1984) and therefore it is perhaps not surprising that it is an attractant for mosquitoes that feed predominantly on these animals. Many Culex species are ornithophilic or anthropophilic, and therefore, may not respond to octenol. Although the compound has also been found in human sweat (Cork, 1996), there is no information about its role on host-finding behaviour of African anthropophilic mosquitoes in the field.

Culex quinquefasciatus did not show a positive response to acetone, a chemical present in the breath of vertebrates, but in A. gambiae and Anopheles stephensi Liston it has been observed to cause strong behavioural responses (Takken $e t$ al., 1997). In addition, the mosquito responded poorly to butyric acid in our experiments. Butyric acid has been implicated in host attraction for mosquitoes (Ikeshoji, 1993) and the frequency with which butyric acid-sensitive cells are found in Aedes epactius Dyar \& Knab suggests that this volatile is an important olfactory cue for this species (Bowen, 1995). Butyric acid is present in low to moderate concentrations in human dermal, faecal and urinary secretions as a by-product of bacterial metabolism (Orlowski, 1966 as cited by Bowen, 1995).

In a separate study (Mboera \& Takken, 1999) we found that $C$. quinquefasciatus was significantly more attractive to a human host than to carbon dioxide, which accounted for $25 \%$ of the attraction. In a field study in South Africa, Dekker \& Takken (1998) reported a similar effect of carbon dioxide. It can be concluded that carbon dioxide is one of the stimuli to which C. quinquefasciatus is attracted, and the addition of human foot odour enhanced the response to the odourbaited trap. Further studies are likely to reveal the active compounds present in the foot odour.

\section{Acknowledgements}

The authors wish to thank Noel Kimambo, Jerry Kimambo and Aza Kimambo for their excellent field assistance. Dr Andrew Kitua, Director General, National Institute for Medical Research is thanked for permission to publish. Professors C.F. Curtis and J.C. van Lenteren and Dr B.G.J. Knols are thanked for their comments on the earlier version of the manuscript. The CFG traps were generously made available by the American Biophysics Corporation, East Greenwich, Rhode Island, USA. The study received financial assistance from the Tanzania Health Research Training Funds and from the EU-DG XII. 


\section{References}

Becker, N., Zgomba, M., Petric, D. \& Ludwig, M. (1995) Comparison of carbon dioxide, octenol, and a host-odour as mosquito attractants in the upper Rhine Valley, Germany. Medical and Veterinary Entomology 9, 377-380.

Bowen, M.F. (1995) Sensilla basiconica (grooved pegs) on the antennae of female mosquitoes: electrophysiology and morphology. Entomologia Experimentalis et Applicata 77, 233-238.

Bursell, E., Gough, A.J.E., Beevor, P.S., Cork, A., Hall, D.R. \& Vale, G.A. (1988) Identification of components of cattle urine attractive to tsetse flies, Glossina spp. (Diptera: Glossinidae). Bulletin of Entomological Research 78, 281-291.

Carlson, D.A., Smith, N., Gouck, H.K. \& Godwin, D.R. (1973) Yellow fever mosquitoes: compounds related to lactic acid that attract females. Journal of Economic Entomology 66, 329-331.

Cork, A. (1996) Olfactory basis of host location by mosquitoes and other haematophagous Diptera. pp. 71-88 in Cardew, G. (Ed.) Olfaction in mosquito-host interactions. Ciba Foundation Symposium No. 200, Chichester, Wiley.

Cork, A. \& Park, K.C. (1996) Identification of electrophysiologically-active compounds for the malaria mosquito, Anopheles gambiae, in human sweat extracts. Medical and Veterinary Entomology 10, 269-276.

Costantini, C., Gibson, G., Sagnon, N., Della Torre, A., Brady, J. \& Coluzzi, M. (1996) Mosquito responses to carbon dioxide in a West African Sudan savanna village. Medical and Veterinary Entomology 10, 220-227.

Dekker, T. \& Takken, W. (1998) Differential responses of mosquito sibling species Anopheles arabiensis and An. quadriannulatus to carbon dioxide, a man or a calf. Medical and Veterinary Entomology 12, 136-140.

Geier, M., Sass, H. \& Boeckh, J. (1996) A search for components in human body odour that attract females of Aedes aegypti. pp. 132-148 in Cardew, G. (Ed.) Olfaction in mosquito-host interactions. Ciba Foundation Symposium No. 200, Chichester, Wiley.

Gibson, G. (1996) Genetics, ecology and behaviour of anophelines. pp. 22-45 in Cardew, G. (Ed.) Olfaction in mosquito-host interactions. Ciba Foundation Symposium No. 200, Chichester, Wiley

Gillies, M.T. (1988) Anopheline mosquitoes: vector behaviour and bionomics. pp. 453-485 in Wernsdorfer, W.H. \& McGregor, I. (Eds) Malaria principles and practice of malariology. Edinburgh ,Churchill Livingstone.

Haddow, A.J. (1942) The mosquito fauna and climate of native huts at Kisumu, Kenya. Bulletin of Entomological Research 33, 91-142.

Hall, D.R., Beevor, P.S., Cork, A., Nesbitt, B.F. \& Vale, G.A. (1984) 1-octen-3-ol: a potent olfactory stimuli and attractant for tsetse isolated from cattle odours. Insect Science and its Application 5, 335-339.

Hassanali, A., McDowell, P.C., Owaga, M.L.A. \& Saini, R.K. (1986) Identification of tsetse attractants from excretory products of a wild host animal, Syncerus caffer. Insect Science and its Application 7, 5-9.

Ikeshoji, T. (1993) Attractive physical and chemical stimuli for mosquito control. Sumitomo Pyrethroid World, Spring issue, pp. 3-8.

Kline, D.L. (1994) Olfactory attractants for mosquito surveillance and control: 1-octen-3-ol. Journal of the American Mosquito Control Association 10, 280-287.
Kline, D.L. (1998) Olfactory responses and field attraction of mosquitoes to volatiles from Limburger cheese and human foot odor. Journal of Vector Ecology 23, 186-194.

Kline, D.L. (1999) Comparison of two American Biophysics mosquito traps: the professional and a new counterflow geometry trap. Journal of the American Mosquito Control Association, 15, 276-282.

Kline, D.L. \& Lemire, G.F. (1995) Field evaluation of heat as an added attractant to traps baited with carbon dioxide and octenol for Aedes taeniorhynchus. Journal of the American Mosquito Control Association 11, 454-456.

Kline, D.L., Wood, J.R. \& Morris, C.D. (1990) Evaluation of 1octen-3-ol as an attractant for Coquillettidia perturbans, Mansonia spp. and Culex spp. associated with phosphate mining operations. Journal of the American Mosquito Control Association 6, 605-611.

Knols, B.G.J., van Loon, J.J.A., Cork, A., Robinson, R.D., Adam, W., Meijerink, J., De Jong, R. \& Takken, W. (1997) Behavioural and electrophysiological responses of the female malaria mosquito Anopheles gambiae (Diptera: Culicidae) to Limburger cheese volatiles. Bulletin of Entomological Research 87, 151-159.

Laarman, J.J. (1958) The host-seeking behaviour of anopheline mosquitoes. Tropical aand Geographical Medicine 10, 293-305.

Mboera, L.E.G. \& Takken, W. (1997) Carbon dioxide chemotropism in mosquitoes (Diptera: Culicidae) and its potential in vector surveillance and management programmes. Review of Medical and Veterinary Entomology $85,355-368$.

Mboera, L.E.G. \& Takken, W. (1999) Odour-mediated host preference of Culex quinquefasciatus in Tanzania. Entomologia Experimentalis et Applicata 92, 83-88.

Mboera, L.E.G., Knols, B.G.J., Takken, W. \& Della Torre, A. (1997) The response of Anopheles gambiae s.l. and A. funestus (Diptera: Culicidae) to tents baited with human odour or carbon dioxide in Tanzania. Bulletin of Entomological Research 87, 173-178.

Mboera, L.E.G., Knols, B.G.J, Takken, W. \& Huisman, P.W.T. (1998) Olfactory responses of female Culex quinquefasciatus Say (Diptera: Culicidae) in a dual-choice olfactometer. Journal of Vector Ecology 23, 107-113.

Mboera, L.E.G., Knols, B.G.J., Braks, M.A.H. \& Takken, W. (2000) Comparison of carbon dioxide baited sampling systems for sampling an outdoor mosquito population in Tanzania. Medical and Veterinary Entomology, in press.

Nicolaides, N. (1974) Skin lipids: their biochemical uniqueness. Science 186, 19-26.

Ritchie, S.A. \& Kline, D.L. (1995) Comparison of CDC and EVS light traps baited with carbon dioxide and octenol for trapping mosquitoes in Brisbane, Queensland (Diptera: Culicidae). Journal of the Australian Entomological Society 34, 215-218.

Snedecor, G.W. \& Cochran, W.G. (1989) Statistical methods. 8th edn. pp. 268-271. Iowa State University Press.

Sudia, W.D. \& Chamberlain, R.W. (1962) Battery-operated light trap, an improved model. Mosquito News 22, 126-129.

Takken, W. \& Knols, B.G.J. (1999) Odor-mediated behaviour of Afrotropical malaria mosquitoes. Annual Review of Entomology 44, 131-157.

Takken, W., Dekker, T. \& Wijnholds, Y.G. (1997) Odormediated flight behavior of Anopheles gambiae Giles s.s. and An. stephensi Liston in response to $\mathrm{CO}_{2}$, acetone and 1octen-3-ol. Journal of Insect Behavior 10, 395-407.

(Accepted 9 March 2000)

(c) CAB International, 2000 


\title{
Pheromones of Non-Lepidopteran Insects Associated with Agricultural Plants
}

\author{
Edited by J Hardie, Department of Biology, Imperial College at Silwood Park, UK and \\ A K Minks, IPO-DLO, Wageningen, The Netherlands
}

September $1999 \quad 480$ pages $\mathrm{HB}$

ISBN 0851993451

E75.00 (US\$140.00)

Readership: Entomology and crop protection.

Since the identification of insect pheromones in the late 1950s, attention has often focused on the use of these potent behaviour-modifying chemicals as pest control agents. Much of this interest has concentrated on Lepidoptera, particularly moths.

In addressing this topic in other insect orders, this multi-author book fills this current gap in the literature. It presents research from leading authorities on the most important insect groups, and details the current progress of research in these areas. Applications of the research to agricultural systems around the world, and possible mechanisms for sustainable crop protection, are considered.

This book is essential reading for students and researchers in entomology and crop protection.

\section{Contents:}

Part I: Pests

- Fruit Flies, PJ Landolt, USDA-ARS, Yakima Agricultural Research Laboratory, USA and A L Averill, University of Massachusetts, USA

- Gall Midges, M O Harris and S P Foster, The Horticulture and Food Research Institute of New Zealand Ltd, New Zealand

- Scarab Beetles, W Soares Leal, National Institute of Sericultural and Entomological Science, Japan

- Sap Beetles, R J Bartelt, USDA-ARS, National Center for Agricultural Utilization Research, USA

- Weevils, R J Bartelt

- Forest Beetles, F Schlyter, Swedish Agricultural University, Sweden and G A Birgersson, Göteborg University, Sweden

- Stored-product Beetles, R Plarre, BAM-Federal Institute of Materials Research and Testing, Germany and $D C$ Vanderwel, University of Winnipeg, Canada

- Sawflies and Seed Wasps, O Anderbrant, Lund University, Sweden

- Aphids, J Hardie, J A Pickett, E M Pow and D W M Smiley, IACR-Rothamsted, UK

- Scale Insects, E Dunkelblum, Agricultural Research Organisation, Israel

- Phytophagous Bugs, H L McBrien and J G Millar, University of California, USA

- Grasshoppers and Locusts, A Hassanali and B Torto, International Centre of Insect Physiology and Ecology (ICIPE), Kenya

- Termites, M Kaib, University of Bayreuth, Germany

Part II: Beneficials

- Predators, J R Aldrich, USDA-ARS Insect Chemical Ecology Laboratory, USA

- Parasitoids, Y Kainoh, University of Tsukuba, Japan

- Parasitoid Hosts, W Powell, IACR-Rothamsted, UK

- Bees, J Pettis, USDA-ARS, Honey Bee Research Laboratory, USA, T Pankiw, University of California, USA and E Plettner, University of Utah, USA

For further information or to order please contact CABI Publishing, UK or an exclusive CABI Publishing

distributor in your area.
Please add $€ 2.50$ per book postage and packing (excluding $U K$ ).

\section{CABI Publishing}

CABI Publishing, CAB International, Wallingford, Oxon OX10 8DE, UK

Tel: +44 (0)1491 832111 Fax: +44 (0)1491 829292 Email: orders@cabi.org

CABI Publishing, CAB International, 10 East 40th Street, Suite 3203, New York, NY 10016, USA

Tel: +1 2124817018 Fax: +1 2126867993 Email:cabi-nao@cabi.org 